\title{
Developing Vocabulary Material using Longtion Autorun Application for Hearing Impaired-Eleventh Grade Learners at SLB Negeri Cerme
}

\author{
Wulan Purnama Sari \\ SLB Negeri Cerme \\ E-mail: wulansari@gmail.com
}

Received: July 10, 2019

Accepted: August 17, 2017

Published: August 31, 2019

doi:10.7575/aiac.ijels.v.1n.1p.1

URL: http://dx.doi.org/10.7575/aiac.ijels.v.1n.1p.1

\begin{abstract}
In the special education, especially hearing impaired learner, the students also learn English, but the learners have the difficulty in learning English vocabulary. There are several reasons for the learners who have the difficulties in learning English vocabulary. One of the reason is because they have physical and mental weakness. Learners of SLB Negeri Cerme also have the difficulties of learning English vocabulary. To help the learners in learning better vocabulary, the researcher will use longtion autorun application to show the picture, text and translation. Longtion autorun application as the base material of learning vocabulary will help learners achieve better vocabularies, which will make the learners more interested and understand the material easily by using some pictures and exercises. The research and development design uses ADDIE instructional design model, to develop vocabulary material using Longtion autorun application for hearing impaired-eleventh grade learners at SLB Negeri Cerme. The research was conducted in SLB Negeri Cerme, involving three hearing impaired learners of eleventh grade. In this research and development, the steps are: need analysis, design, development, implementation, evaluation. The need analysis gave some explanations; First, analysis of interviews with English teacher about the learning need, second, analysis of interviews with learners about their target need and learning need, third, curriculum document analysis. Researcher created a design instruction called material prototype as a framework that was used in developing syllabus and application. Researcher developed a material according to the result of need analysis and design. The activities of the learning are in three phases (pre, whilst, and post) Strategy. From the result of English teacher assessment, the score was 87,5. While the result of learner's questionnaire about the product, the total score was 88,3. It belongs to the good category based on scoring. This second draft of material was considered as the final draft. The overall conclusion appears that the learners interested when they learnt English using Longtion autorun application because the materials were easy to understand, interesting, and suitable for eleventh grade hearing impaired learners. The researcher gives some recommendation, the next researcher could conduct the similar project to do the same research with different level and focus in order to enrich the variety of the research. For the teacher, this product could be used as a combination when they teach English to introduce the simple English vocabulary to the learners.
\end{abstract}

Key words: vocabulary, longtion autorun, hearing-impaired learners.

\section{Introduction}

English is a foreign language that is taught in formal education. English is not only taught to the normal learners, but also for the disabilities. The Indonesian government realized that English is important to support and enhance the process of the development in Indonesia and to absorb the development of science and technology. Special education is an education for learners who have difficulty in joining the learning process due to physical, emotional, mental, and social conditions. Children who have disorder are very meaningful because it gives a strong foundation that children with disabilities need the same opportunities as it is granted to the normal children in terms of learning and teaching. Therefore, the government attaches subject at the school for the learners who have physical weakness and mental retardation, or in Indonesia it is usually known as special education. In English subject, vocabulary is one of the language components that has to be learned. Vocabulary is a key link to master four other skills in language learning, they are: speaking, listening, reading and writing (Moats, 2005). Vocabulary development is the most important part of the others which should be mastered in the process of the learning of reading by the learners before they learn other skills, it means that the development of the vocabulary can give positive impact that can help children to apply their ideas in speaking so their lack of vocabularies doesn't affect their idea which that will be conveyed. Vocabulary is the central of language teaching, by mastering vocabulary, people can express their ideas and understand the meaning of what the 
opponent of communication have been said. Moreover, In order to build up good communication in foreign language, learners have to acquire and know how to use them accurately.

Learning vocabulary in the level of hearing impaired learners does not need to be learned deeply, but they emphasize more on daily application for daily communication. Deaf learners are weak in their level of vocabulary knowledge (Luckner \& Cooke, 2010). Learning a language for hearing impaired learners is used to observe their emotional characteristics and intelligence. Consequently, many learners who are deaf may not have learned the academic language and necessary vocabulary key for understanding the content of information. As a result, they have difficulty with the vocabulary and concept demanded in many content-area discussions, lessons, and material presented in the textbook. Deaf learners often find some obstacle and difficulties in communication because some of them lost their total ability to listen while the rest lost some abilities in listening or hearing the sounds. This condition makes the deaf learners to deliver their ideas, expressions and thought toward each other in difficult ways. Furthermore, the other obstacles faced by the deaf learners are in development of language competencies. Therefore, they cannot hear and listen well of every sound of language which is spoken by others. Consequently, they will get less vocabulary and get difficulty in communicating to others.

According to El-Zraigat \& Smadi (2012) hearing-impaired learners need special services to be offered to them with the needed equipment in order to meet their unique needs. For example, they need special technique that meets their developmental tasks. In order to assist the hearing impaired learners in teaching learning process, there are special education services which solve their problem. One of the treatments and strategies is teaching through visualization. In this case, the teacher serves some appropriate and interesting pictures through a Longtion autorun application which is reflected from the topic. Text and picture are the most effective type of vocabulary annotation (Yeh, Y., \& Wang, C., 2003). Explaining and delivering lessons through picture will ease the hearing impaired learners to acquire and understand some new vocabularies and enhance learners' motivation in learning. According to Zamfirov, M., \& Saeva, S. (2013) the application of computer based teaching strategies with hearing impaired learners in English classes is highly effective. Yovkova, B. (2016) also stated that learning with the help of well-designed interactive multimedia applications has a potential to increase the effectiveness of vocabulary acquisition among the children with hearing loss. There are many visual stimuli and manual commands during the teaching-learning process. In addition, the hearing impaired learners are more likely need some types of vocabulary exercise in order to test their competency progress and to apply their understanding of new vocabulary which they have got. Thus, the vocabulary material should be designed in form of longtion autorun application because it is best in visualization and help the learners to learn new simple vocabularies through pictures, simple explanations and exercises, so they will be interested and will get new knowledge when they learn something new.

Hearing impaired learners in $S L B$ cannot hear perfectly, they only can hear small voices from the opponent or their teacher. Similarly, the learners in eleventh grade in $S L B$ also face the difficulty in learning because they have less vocabulary which can help them reach their knowledge about something around them.

Regarding these problems, the researcher attempts to develop a vocabulary material which appropriate and can make the learners understand the material easily. Moreover, in term of elevating the critical thinking of the learners, the researcher tries to develop vocabulary material using Longtion autorun application which will make the learners more interested and understand it easily by serving some of explanations and exercises.

\section{Hearing Impaired Learner}

El-Zraigat (2013) stated that hearing impaired learner has a mall function of all or some parts of hearing ability because someone got problems or lost their hearing ability and it will give the impact on their language development They are considered as learners with special needs.

Hearing impaired learner is being deprived of the sense of hearing, not only defined that they cannot hear the sounds, but they also have the lack of access to many helpful and promising experiences of both individual and social life as well (Zamfirov \& Saeva, 2013).

Deaf learner have troubles in their hearing sense, so, they will get obstacles to respond some outside sounds and face the problems to communicate or deliver their ideas toward peers hearing impaired or normal learner. Those problems will limit individual development, intelligence, and performance competency in society. According to Parhoon, Hassanzadeh, Parhoon, \& Movallali, (2014) hearing-impaired learner needs special teechnique and special education services reflecting their special needs as exceptional learners.

Considering on those experts above, the researcher concludes that hearing impaired child is someone who has lost or breaks some part of or all of his/her hearing sensor so their hearing sense can not be normally functioned, they usually get helped by a hearing aid.

\section{Vocabulary for Hearing-Impaired Learners}

Vocabulary is one of the most important aspects of the language to be learned. Vocabulary has been defined as "the storehouse of word meanings that we draw on to comprehend what is said to us, express our thoughts, or interpret what we read" (Moats, 2005, p. 7). It means that vocabulary is part of the English and vocabulary is needed for the reader to easily understands the English language in the four skills to achieve a certain level of understanding. Based on Karasu, 
Girgin, Uzuner, \& Kaya, (2016) learners who have richer vocabulary knowledge and improved the language level are better in literacy skills.

Hearing impaired learners lack of communication with their peers in the critical area of vocabulary knowledge because of their sensory limitations (Massaro \& Light, 2004). Word selection is important especially when we teach learners with low vocabularies; they need to know the words deeply to access the specific content-words they encounter in the text. One central importance of vocabulary knowledge is to understand the world and to gain the language ability. Children experience language delays because of specific language impairment benefit once this level of word knowledge is obtained. It follows that the increase of the effectiveness of vocabulary learning offers a promising opportunity to improve conceptual knowledge and language competence for all individuals, whether or not they get disadvantages because of sensory limitations, learning disabilities, or social condition.

Vocabulary development of hearing impaired individuals have shown that there is a strong relationship between reading comprehension and vocabulary development. Furthermore, in addition to common vocabulary, it is important to develop occupational vocabulary in hearing impaired learners for their future occupational success. Therefore, it is important to conduct research on vocabulary development for hearing impaired learners. Vocabulary has important aspect which will meet in every competence. Understanding vocabulary will determine the result of knowledge that someone has. Vocabulary can be improved by understanding reading text and it shows someone's intelligent. It is important to learn vocabulary because it improves the skill of English. There are so many advantages if the learners can master vocabulary well.

\section{Longtion Autorun Application}

In this study, the researcher uses Computer Assisted Language Learning (CALL) program-which is Longtion Autorun Application - to develop vocabulary material for hearing impaired learners on the eleventh grade. According to Naraghizadeh \& Barimani (2013) Longtion Autorun Application is a Computer Assisted Language Learning (CALL) in modern language teaching and learning arena, it involves the use of technology in the form of computers ranging from software. It means learners can learn language in any context with, through, and around computer technologies. Technology has surely influenced human activities and education. Applying technology to the learning is becoming an important thing. The use of computer in educational setting has increased from the combination of educational needs and technological means. Longtion Autorun Application is increasingly integrated into curricula to promote the development of all skills, especially for vocabulary aspect.

Based on Miles \& Ja Kwon (2008) CALL is increasingly seen as an attractive option for learning. Longtion Autorun Application is a powerful visual tool to create professional autoplay interfaces and presentations to your $\mathrm{cd} / \mathrm{dvds}$. It is the easiest way to create, edit professional autoplay interface and generate autorun files for cd/dvds, just click, point, place and run. So every material has a good, fast, and simple visual. Autorun is easy to learn by demos and wizards. Even though it is very easy to learn and use, it has everything you need to develop professional software applications. So, every teacher can be easily develop media for English teaching and learning process according to the statement that the researcher thinks about the Longtion Autorun Application. It will be used to create an application of vocabulary material which is interesting and fun for the learners because the way of how to operate the program is simple and easy. It is appropriate for the eleventh grade hearing impaired learners, longtion autorun have 25 objects: panel, tab notebook, tab sheet, group box, scroll box, splitter, button, Image button, label, text, image, bevel, fade button, fade label, fade text, shape, balloon, note, slide show, memo, rich text, web browser, media player, flash player, pdf reader. To make longtion autorun application for interactive vocabulary material, you can mix this application with another application.

\section{The History of Three Phases (Pre, Whilst, and Post) Strategy}

Once the domain and area of construction have been identified, then the reasearcher designs a lesson plan. There are some formats of lesson plan. As a good language teacher, they should have good lesson plan which contain three critical components as stated by Rhea (2001) there are domain and area of instruction, learning outcome and materials.

Focus on materials, the teacher should have a variety of ways for learners to connect their experiences to the lesson. According to Hommond (1992) the curriculum design and program planning in school have to be based on: theoretical understanding of language and literacy ; initial and ongoing assessment of learners ; analysis of learners' need and goals ; analysis of demands of language content.

We better understand the ways, conditions, and spirit in which children do their best learning and are able to make school into a place where they can use and improve the style of thinking and learning natural to them, we may be able to prevent much failure.

There are steps in teaching in order to the learners understand the lesson. It's called Three Phases Strategy (Pre, Whilst, and Post Strategy). Each of phases in Three Phases Strategy is involved learners to have activities when having teaching and learning process. 
The Rules of Three Phases (Pre, Whilst, and Post) Strategy

This strategy consists of three stages. There are Pre-Teaching, While- Teaching and Post-Teaching. That can help teacher to prepare learners for and guide them, so that they will learn from them most effectively.

The first is Pre-Teaching, it is focusing on prior knowledge activates of learners. This stage contains of building the context of the topic which should involve the learner in as many ways as possible. One of the purpose is to acknowledge the different contexts, experiences, and background knowledge of learners that will influence how they learn from a topic. According to Jacobs (2010) in the stage of Pre-Teaching, teachers prepare learners for achieving learning goals by providing purposes for learning, activating and organizing broadening learners background knowledge and experience that will be relevant to learning, previewing a lesson's vocabulary and central concepts, promoting $\mathrm{s}$ learners' motivation through their development of questions and hypotheses.

The second is While-Teaching, describes what will be learned and how it will be learned. As stated by Jacobs (2010) in the stage of While-Teaching, learners engage in problem-solving, exploration, and practice by engaging in focused study (e.g., analysis) integrating the "given" they bring to learning process with the new lesson, practicing new skills by following teachers' models.

The last is Post-Teaching, that is the closing of the lesson. The teacher should reinforce the important generalizations learned from the lesson and regarding assessment. Based on Jacobs (2010) learners set their learning by answers through additional analysis, testing the validity of their generalizations about their learning before assessment, providing learners with means to understand their own learning processes, preparing for evaluation of learning.

\section{Methods}

The researcher conducts the research in the school for special needs. When the researcher conducts in special education which focuses on hearing impaired learners at eleventh grade, researcher sees the syllabus and the textbook from the government, it can be concluded that the rules are the same as on normal school does. But, it is difficult to apply the syllabus for learners with special need, particularly learners with hearing loss. From those facts the researcher makes research with the development of teaching materials that is suitable with their needs. In this research, the researcher designs the study using Research and Development (R\&D). The researcher chooses this research design because this study is designed to develop material, especially in vocabulary material for hearing impaired-eleventh grade learner at SLB Negeri Cerme. In this study, the researcher attempts to use ADDIE model. This is a chart of the ADDIE model From "Instructional System Design" by McGriff (2000).

Procedure of Development

Analysis (Need Analysis)

In this part, the need analysis is divided into two, they are target needs and learning needs. Target needs are related to the content of the materials to be developed. Learning needs are related to the way the learners learn the vocabulary materials. The researcher conducts an interview for three learners at eleventh grade and English teacher at eleventh grade as well in SLB Negeri Cerme to get some informations about need analysis in order to develope vocabulary material.

First is interview the learners, the points for interview of learner can be broken down into target need and learning need. The main points of target needs of interview are:

1. The necessities of learner in learning vocabulary

2. The lacks that might be faced by learner in learning vocabulary

3. The wants of learner in vocabulary material

The main points of learning need interview are:

1. The learner's interested in media that used in learning vocabulary

2. The learner's interested in strategy that used in learning vocabulary

3. The learner's interested in the exercise that used in learning vocabulary

Second, conduct an interview to the English teacher, the points for this interview are as follows:

1. The curriculum that applied in English learning

2. The media that used in vocabulary teaching

3. The procedure of learning activity

4. The appropriate tasks for the material

In this phase, the researcher also analysis English curriculum as a reference to develop the material. The result of analyzing English curriculum and the interview will be a guidance for the researcher in designing instructional goals and some tasks for the learners.

Design 
From the findings of previous analyses, the researcher needs to plan how to achieve the instructional goals, pays attention to the effectiveness of the vocabulary material elements and design criteria for assessment.

In this phase the researcher will make design of the prototype, create a prototype draft as a framework used in developing syllabus and application. The prototype is related to the general framework, and spesific draft for detail of task activities.

It is included the internal aspects and external aspects. Internal aspect of the program contains of material and interface of the software, while the external aspect will be the physical form of the software. The physical system for example can be in the form of Compact Disk.

After the prototype is finished, the researcher then try to find out what has been left in the design and improve it again for the development phase. The improvement in this phase will reduce the double work during development by catching small mistakes.

\section{Development}

After passing through the design phase, the next step is developing material. In this major step, researcher uses the technologies and media of computer that is longtion autorun application to deliver the lessons.

After the first prototype is developed in the design phase, the researcher develop a syllabus and the application that will support the teaching learning process. The application will be displayed and tested, for the things that aren't working in the software will be removed and the performance will be enhanced.

This phase will be done by the researcher, the software will be run and see the result whether it can run well or not and to check if there is something that doesn't work.

\section{Implementation}

In this step the researcher will try out the product which has been developed by the researcher. The product will be implemented in the classroom to find out how the software will work for the learners and to figure out what kind of support is needed to make it suitable for the learners.

The learner will learn the material by computer media using longtion autorun application which is the focus on the learning process. The teacher also gives a guidance.

At the end of the try out, the researcher will give questionnaire to the learners in order to know their comment about the material. It has the purpose to know whether the vocabulary is kind of interesting material and easy to learn or not. In addition, it will also be used as feedback for the researcher to improve the vocabulary material which was created by the researcher before.

\section{Evaluation}

In this phase the researcher will evaluate the learning processes and its outcomes. The instruction will not be completed until it shows the learners' understanding about the instructional goals. The researcher will do evaluations include:

\section{Formative Evaluation}

The results of formative evaluation during the development of vocabulary material has the purpose in establishing the suitability of objectives, contents, learning methods, materials, and the delivery of the vocabulary course.

\section{Summative Evaluation}

Summative evaluation will be conducted at the end of the vocabulary instruction. It is to evaluate the effectiveness of the instruction.

\section{Revision of Instruction}

Revision is a continual process. Whenever an instructor finds parts in the instruction that is difficult or unclear for students, revision will immediately fix the material.

\section{Findings}

The implementation was done in the classroom, there were 3 learners. There were three steps of the implementation, pre-teaching, while-teaching, and post-teaching.

In the pre-teaching, teacher gave brainstroming to the learners in order to activate the vocabulary's prior knowledge of learners. Teacher gave the question related to the topic. Then teacher invited the students to watch a video in longtion autorun application that related to the topic. Teacher also informed them to pay attention on the video and after watching the video, learners write the vocabularies on the white board. After that they watched the video. Then write down the vocabularies which exist in video on the white board.

In the while teaching stage, teacher gave some vocabularies to the learners by showing picture, word and also the translation through longtion autorun applicaticon in computer. After that asked learners to write the vocabularies on their own book. 
In the post teaching, teacher gave feedback to the learners about what they had learned. Teacher gave quiz to the learners through quiz game in longtion autorun application, in order to test the learners's understanding of the lesson and helped learners to remember what they had learned.

\section{The Evaluation of the Material}

After the first draft of the material assessed by the expert. Researcher carried out tests on the first draft of the material. This was called the try-out 1 . After the try-out 1 conducted, researcher got feedback which was used as an evaluation to revise the first draft of the material. The table below presents about the revisions of first draft of material.

Evaluation

1. Doesn't need the deep explanation video about procedure/report text

2. The application need mini dictionary

\section{Revision}

1. Directly example of procedure/report text video

2. Add mini dictionary in every chapter

Table 4.6 : Evaluation of the material

Final Product

After passing the process of revision, the draft of material was called the second draft. Researcher had carried out the second draft or it could be called try-out 2. After try-out 2 had been conducted, the researcher asked English teacher and eleventh grade of hearing impaired learners to assess the second draft of the material.

From the result of English teacher assessment on the table above, the score is 87,5. While the result of learner's questionnaire about the product, the total score was 88,3 . It belongs to good category based on scoring. This second draft of material was considered as the final draft.

\section{Conclusion}

Teaching process for hearing impaired learner emphasizes on visual and the use of picture which help them to know what the point from the matter what they learn easily, because the pictures represent some words, meaning, thing or activity. In English, hearing impaired learner commonly study vocabulary skill. They don't learn English deeply, such as learn grammar and pronunciation. Because of their weaknesses, they also can't study speaking and listening skill. The use of picture that combine with multimedia computer application also enhances the hearing impaired learners imagination about what they see in the picture and make them more interest in learn vocabulary. That is the reason why the researcher develops vocabulary material using longtion autorun application for hearing impaired learners. The appropriate strategy in teaching and learning is Three Phases Strategy (Pre, Whilst, and Post Strategy).

Based on the result of need analysis from interview with the English teacher, the researcher got information about the condition of the school, the school still used KTSP as reference in teaching and learning process. The researcher also knew about the way how the teacher taught the lesson. The teacher in this school did not use media. Then, about the condition of the eleventh grade hearing impaired learners, they seemed enthusiastic when they learnt English. Then, based on the result of learners' interview that most of learners stated that they liked learning English, but sometimes they also faced 2 difficulties about vocabulary because they only knew few vocabularies. All of the learners also stated that they were interested in learning English vocabulary using longtion autorun application which they never knew before. The researcher concluded that the learners were very interested when they learn English but there was no media like picture and no interesting learning process, so the researcher made vocabulary material in form of longtion autorun application with some colorful and interesting pictures. The researcher developed the material into two topics which consisted of vocabulary skill.

Based on the result of learner's questionnaire about the product, the total score was 88,3 . The result of learners opinion after try out that all of the materials which was taught to them was very interesting. They were also interested when they learnt English using longtion autorun application because the materials were easy to understand. Then based on the result from expert validator checklist, the score of the application was 87,5. It meant that the vocabulary material was very suitable to use for eleventh grade hearing impaired learners.

\section{References}

Aldoobie, N. (2015). ADDIE Model. American International Journal of Contemporary Research. Vol. 5, No. 6.

Danks, S. (2011). The ADDIE Model: Designing, Evaluating Instructional Coach

Effectiveness. ASQ Primary and Secondary Education Brief August.

Vol. 4, No. 5. 
Dick, W., L. Carey, and J.O. Carey. (2014). The Systematic Design of Instruction, 8th edition. Boston: Allyn and Bacon.

El-Zraigat, I. A. (2013). Assessing Special Needs of Students with Hearing Impairment in Jordan and Its Relation to Some Variables. International Education Studies; Vol. 6, No. 2.

El-Zraigat, I. A., \& Smadi, Y. (2012). Challenges of Educating Students Who are Deaf and Hard-Of-Hearing in Jordan. International Journal of Humanities and Social Science. Vol. 2 No. 8.

Hommond, J. (1992). English for Social Purposes. Sydney :NCELTR

Hutchinson, T., \& Waters, A. (1987). English for Specific Purposes: A LearningCentred Approach. Cambridge: Cambridge University Press.

Jacobs, V. A. (2010). Pre-, Guided-, and Post-learning Purposes and Strategies. H-810c. Downloaded 17-2-10:

http://www.marion.k12.ky.us/Strategies/Social/math/glossary.htm\#graphic organizer)

Karasu, G., Girgin, U., Uzuner, Y., \& Kaya, Z. (2016). Examining Vocabulary

Development Strategies Applied to Hearing Impaired Youths. Turkiye:

Anadolu University.

Lehman, B. L. (2007). A.D.D.I.E.: A Proactive Approach to Employee Training \&

Development. Rising Sun Consultants.

Luckner, J. L., \& Cooke, C. (2010). A Summary of the Vocabulary Research With

Students Who Are Deaf or Hard of Hearing. America: Gallaudet

University Press.

Massaro, D. W., \& Light, J. (2004). Improving the Vocabulary of Children with

Hearing Loss. The Volta Review, 104(3): 141-174.

McGriff, S. J. (2000). Instructional System Design. College of Education, Penn

State University.

Miles, S., \& Ja Kwon, C. (2008). Benefits of Using CALL Vocabulary Programs

to Provide Systematic Word Recycling. English Teaching, Vol. 63, No.1,

Spring.

Moats, L. C. (2005). Language essentials for teachers of reading and spelling:

Module 4. Boston: Sopris West Educational Services.

Naraghizadeh, N., \& Barimani, S. (2013). The Effect of CALL on the Vocabulary

Learning of Iranian EFL Learners. Journal of Academic and Applied

Studies Vol. 3 (8), pp. 1-12.

Parhoon, K., Hassanzadeh, S., Parhoon, H., \& Movallali, G. (2014). Educational Needs Assessment of Student with Hearing Impairment in Inclusive School.

International Journal of Academic Research in Progressive Education and Developmen.Vol. 3, No. 2.

Rhea, A. A. (2001). Promoting the Gift of Literacy. USA: Pearson Education

Company.

Sink, D. L. (2014). Design Models and Learning Theories for Adults. America:

American Society for Training \& Development.

Yeh, Y., \& Wang, C. (2003). Effects of Multimedia Vocabulary Annotations and

Learning Styles on Vocabulary Learning. CALICO Journal, 21 (1), p-p

131-144.

Yovkova, B. (2016). Interactive Instructional Multimedia in Vocabulary

Development of Children with Hearing Loss. Bulgaria: Sofia University.

Zamfirov, M., \& Saeva, S. (2013). Computer Enhanced English Language Tool

for Students with Hearing Loss - A Bulgarian study. Educational

Technology \& Society, 16 (3), 259-273. 